\title{
Tuberculosis in the intensive care unit: A retrospective descriptive cohort study with determination of a predictive fatality score
}

\author{
Sandrine Valade $\mathrm{MD}^{1}$, Laurent Raskine $\mathrm{MD}^{2}$, Mounir Aout $\mathrm{PhD}^{3}$, Isabelle Malissin $\mathrm{MD}^{1}$, Pierre Brun $\mathrm{MD}^{1}$, \\ Nicolas Deye $\mathrm{MD}^{1}$, Frédéric J Baud $\mathrm{MD}^{1,4}$, Bruno Megarbane MD PhD ${ }^{1,4}$
}

\begin{abstract}
S Valade, L Raskine, M Aout, et al. Tuberculosis in the intensive care unit: A retrospective descriptive cohort study with determination of a predictive fatality score. Can J Infect Dis Med Microbiol 2012;23(4):173-178.
\end{abstract}

BACKGROUND: Despite effective treatments, tuberculosis-related mortality remains high among patients requiring admission to the intensive care unit (ICU).

OBJECTIVE: To determine prognostic factors of death in tuberculosis patients admitted to the ICU, and to develop a simple predictive scoring system.

METHODS: A 10-year, retrospective study of 53 patients admitted consecutively to the Hôpitaux de Paris, Hôpital Lariboisière (Paris, France) ICU with confirmed tuberculosis, was conducted. A multivariate analysis was performed to identify risk factors for death. A predictive fatality score was determined.

RESULTS: Diagnoses included pulmonary tuberculosis (96\%) and tuberculous encephalomeningitis (26\%). Patients required mechanical ventilation $(45 \%)$ and vasopressor infusion $(28 \%)$ on admission. Twenty patients (38\%) died, related to direct tuberculosis-induced organ failure $(n=5)$, pulmonary bacterial coinfections $(n=14)$ and pulmonary embolism $(\mathrm{n}=1)$. Using a multivariate analysis, three independent factors on ICU admission were predictive of fatality: miliary pulmonary tuberculosis (OR 9.04 [95\% CI 1.25 to 65.30]), mechanical ventilation (OR 11.36 [95\% CI 1.55 to 83.48$]$ ) and vasopressor requirement (OR 8.45 [95\% CI 1.29 to 55.18]). A score generated by summing these three independent variables was effective at predicting fatality with an area under the ROC curve of 0.92 ( $95 \%$ CI 0.85 to 0.98 ).

CONCLUSIONS: Fatalities remain high in patients admitted to the ICU with tuberculosis. Miliary pulmonary tuberculosis, mechanical ventilation and vasopressor requirement on admission were predictive of death.

\section{La tuberculose à l'unité de soins intensifs : une étude de cohorte descriptive rétrospective et la détermination d'un indice prédictif de fatalité}

\begin{abstract}
HISTORIQUE : Malgré des traitements efficaces, la mortalité liée à la tuberculose demeure élevée chez les patients qui doivent être hospitalisés à l'unité de soins intensifs (USI).

OBJECTIF : Déterminer les facteurs pronostiques de décès chez les patients tuberculeux admis à l'USI et élaborer un système d'indice prédictif simple.

MÉTHODOLOGIE : Les chercheurs ont mené une étude rétrospective d'une durée de dix ans auprès de 53 patients hospitalisés consécutivement à l'USI de l'Hôpital Lariboisière des Hôpitaux de Paris, en France, en raison d'une tuberculose confirmée. Ils ont procédé à une analyse multivariée pour déterminer les facteurs de risque de décès et ont établi un indice prédictif de fatalité.
\end{abstract}

RÉSULTATS : Les diagnostics incluaient une tuberculose pulmonaire (96\%) et une encéphaloméningite tuberculeuse (26\%). Les patients avaient besoin d'une ventilation mécanique (45\%) et d'une perfusion de vasopresseur (28\%) à l'admission. Vingt patients (38\%) sont décédés en raison d'une insuffisance organique liée directement à la tuberculose $(n=5)$, de co-infections bactériennes pulmonaires $(n=14)$ et d'une embolie pulmonaire $(\mathrm{n}=1)$. Selon l'analyse multivariée, trois facteurs indépendants à l'admission à l'USI étaient prédictifs d'une fatalité : une tuberculose miliaire (RRR 9,04 [95 \% IC 1,25 à 65,30]), une ventilation mécanique (RRR 11,36 [95\% IC 1,55 à 83,48]) et des besoins vasopressifs (RRR 8,45 [95 \% IC 1,29 à 55,18]). Un indice conforme à la somme de ces trois variables indépendantes était efficace pour prévenir la fatalité, avec une zone sous la courbe ROC de 0,92 (95\% IC 0,85 à 0,98).

CONCLUSIONS : Les décès demeurent élevés chez les patients tuberculeux admis à l'USI. La tuberculose miliaire, la ventilation mécanique et les besoins vasopressifs à l'admission sont prédictifs d'un décès.

Key Words: Death; Intensive care unit; Mycobacterium tuberculosis; Miliary; Predictive factor; Tuberculosis

Tuberculosis remains a major public health issue despite available 1 effective therapies. In 2007, an estimated 1.78 million people died from tuberculosis, which made it the leading infectious cause of fatalities worldwide (1). However, diagnosis may be difficult due to atypical presentations, resulting in delay of specific antibiotic therapy. Rarely, organ failure occurs. Patients with tuberculosis requiring intensive care unit (ICU) admission represent approximately $1 \%$ to $3 \%$ of all patients with tuberculosis (2). Data regarding tuberculosis in the ICU are sparse and generally refer to respiratory failure $(2-8)$. The prognosis for tuberculosis patients appears significantly worse than for individuals experiencing nontuberculous pneumonia requiring mechanical ventilation (7). Our aims were to investigate circumstances surrounding ICU admission leading to the diagnosis of tuberculosis and to determine prognostic factors of death to develop a simple scoring system.

\begin{abstract}
METHODS
Patient selection and definitions

The medical charts of all patients ultimately confirmed to have tuberculosis who were hospitalized in the Hôpitaux de Paris, Hôpital Lariboisière (Paris, France) ICU over a 10-year period (March 2000 to July 2009) were retrospectively reviewed. A patient list of confirmed cases of tuberculosis was obtained from the microbiology laboratory database. Usual clinical and laboratory parameters were collected, and final outcomes of survival or death were recorded. A diagnosis of tuberculosis was based on a positive Mycobacterium tuberculosis culture in one or more biological fluids or biopsied tissue obtained during the hospital stay. Miliary tuberculosis was defined as the presence of disseminated micronodules on chest radiograph or tomography. Organ system dysfunction and acute respiratory distress syndrome (ARDS)
\end{abstract}

${ }^{1}$ Réanimation Médicale et Toxicologique, Université Paris-Diderot; ${ }^{2}$ Laboratoire de Microbiologie; ${ }^{3}$ département de biostatistiques et unité de recherche clinique, Assistance Publique - Hôpitaux de Paris, Hôpital Lariboisière, Paris; ${ }^{4}$ INSERM U705-CNRS, UMR7157, Université Paris-Diderot, Paris, France

Correspondence: Dr Bruno Megarbane, Réanimation Médicale et Toxicologique, Hôpital Lariboisière, 2 rue Ambroise Paré, Paris 75010 , France. Telephone 33-1-49-95-64-91, fax 33-1-49-95-65-78, e-mail bruno-megarbane@wanadoo.fr 
TABLE 1

Characteristics of patients with tuberculosis according to outcome $(n=53)$

\begin{tabular}{|c|c|c|c|c|c|}
\hline & All patients $(n=53)$ & Survivors $(n=33)$ & $\begin{array}{c}\text { Nonsurvivors } \\
(n=20)\end{array}$ & $\begin{array}{c}\text { OR } \\
(95 \% \mathrm{Cl})\end{array}$ & $\mathbf{P}$ \\
\hline \multicolumn{6}{|l|}{ Demographic parameters } \\
\hline Age, years & $41(32-52)$ & $40(30-47)$ & $45(34-55)$ & $5(-7$ to 15$)$ & 0.3 \\
\hline Body mass index, $\mathrm{kg} / \mathrm{m}^{2}$ & $20(17-24)$ & $20(17-26)$ & $21(17-23)$ & $1(-3$ to 5$)$ & 0.9 \\
\hline HIV infection, n (\%) & $12(23)$ & $7(21)$ & $5(25)$ & $4.4(-24.9$ to 33.3$)$ & 0.7 \\
\hline Homeless, n (\%) & $17(32)$ & $7(21)$ & $10(50)$ & $28.8(2.8$ to 54.8$)$ & 0.04 \\
\hline Temperature, ${ }^{\circ} \mathrm{C}$ & $38.7(37.6-39.6)$ & $38.9(37.8-39.9)$ & $38.1(37.3-39.1)$ & $-0.9(-1.8$ to 0.5$)$ & 0.05 \\
\hline Glasgow Coma score & $14(12-15)$ & $15(13-15)$ & $13(7-15)$ & $-2(-7$ to 0$)$ & 0.01 \\
\hline Systolic blood pressure, $\mathrm{mmHg}$ & $96(80-118)$ & $105(94-119)$ & $80(65-104)$ & $-25(-38$ to -2$)$ & 0.004 \\
\hline Heart rate, beats/min & $125(105-143)$ & $119(101-138)$ & $135(121-145)$ & $16(-1$ to 35$)$ & 0.1 \\
\hline Respiratory rate, breaths/min & $31(25-38)$ & $29(24-34)$ & $35(30-45)$ & $6.5(0.1$ to 14$)$ & 0.03 \\
\hline Extrapulmonary involvement, $\mathrm{n}(\%)$ & $15(28)$ & $10(30)$ & $5(25)$ & $-5.3(-29.9$ to 19.3$)$ & 0.7 \\
\hline \multicolumn{6}{|l|}{ Biological parameters } \\
\hline $\mathrm{PaO}_{2} / \mathrm{FiO}_{2}, \mathrm{mmHg}$ & $285(188-385)$ & $347(265-441)$ & $170(109-342)$ & $-177(-288$ to -1$)$ & 0.002 \\
\hline $\mathrm{HCO}_{3}^{-}, \mathrm{mmol} / \mathrm{L}$ & $24.0(20.0-28.0)$ & $24.0(22.0-27.0)$ & $22.5(19.5-28.5)$ & $-1.5(-5$ to 3.5$)$ & 0.4 \\
\hline Plasma lactate concentration, $\mathrm{mmol} / \mathrm{L}$ & $1.9(1.2-3.0)$ & $1.5(1.0-2.4)$ & $2.3(1.8-4.7)$ & $0.8(0.1$ to 3.1$)$ & 0.02 \\
\hline Prothrombin index $* \%$ & $73(59-82)$ & $75(72-86)$ & $61(46-78)$ & $-14(-26$ to 0$)$ & 0.01 \\
\hline Serum creatinine, $\mu \mathrm{mol} / \mathrm{L}$ & $66(52-90)$ & $68(52-81)$ & $63(46-121)$ & $-5(-21$ to 31$)$ & 0.9 \\
\hline C-reactive protein, $\mathrm{mg} / \mathrm{L}$ & $95(32-188)$ & $65(21-134)$ & $122(95-235)$ & 57 (19 to 163$)$ & 0.02 \\
\hline \multicolumn{6}{|l|}{ Physiological score } \\
\hline SAPS II & $31(22-50)$ & $28(20-34)$ & $50(36-69)$ & 22 (13 to 41$)$ & 0.0002 \\
\hline Acute renal injury $^{\dagger}, \mathrm{n}(\%)$ & $5(9)$ & $1(3)$ & $4(20)$ & $17(-10.7$ to 43.2$)$ & 0.06 \\
\hline \multicolumn{6}{|l|}{ Microbiological data } \\
\hline Antituberculosis therapy in the ICU, $\mathrm{n}(\%)$ & $40(75)$ & $21(64)$ & $19(95)$ & $31.4(3.5$ to 55.6$)$ & 0.02 \\
\hline Delay, days & $3(0-21)$ & $4(2-23)$ & $2(0-7)$ & $-2(-19$ to 0$)$ & 0.04 \\
\hline Hemodialysis, n (\%) & $9(17)$ & $1(3)$ & $8(40)$ & 37 (9.8 to 60.8$)$ & 0.001 \\
\hline \multicolumn{6}{|l|}{ Outcome } \\
\hline Length of ICU stay, days & $6(3-16)$ & $6(3-13)$ & $8(3-19)$ & $2(-4$ to 10$)$ & 0.7 \\
\hline Hospital-acquired infections, n (\%) & $11(21)$ & $2(6)$ & $9(45)$ & 38.9 (11.8 to 62.5$)$ & 0.001 \\
\hline
\end{tabular}

Data presented as median (interquartile range) unless otherwise indicated. Bolded values indicate statistical significance. *Prothrombin index (in which a decrease corresponds to an increase in prothrombin time or internationalized normalized ratio) represents the percentage of the patient-to-normal value ratio; ${ }^{\dagger}$ Acute renal injury was determined using the definition and the estimated baseline creatinine according to Bellomo et al (9); ${ }^{\ddagger}$ Delay to the first microbiological proof of tuberculosis: delay between intensice care unit (ICU) admission and the date of either a positive direct examination or a positive culture when the direct examination was negative. $\mathrm{PaO}_{2} / \mathrm{FiO}_{2}$ Ratio of partial pressure of arterial oxygen to the fraction of inspired oxygen; SAPS II Simplified Acute Physiology score II

were assessed using standard definitions. Renal injury was defined according to the Risk, Injury, Failure, Loss and ESRD (RIFLE) criteria (9). Physiological variables measured on admission were used to calculate the Simplified Acute Physiology Score (SAPS) II (10).

Statistical analysis

Continuous variables were expressed as means $( \pm S D)$ or median (interquartile range $[\mathrm{IQR}]$ ) depending on their distribution and compared using Student $t$ tests or, if not applicable, Mann-Whitney $U$ tests. Qualitative variables were reported as frequencies and percentages and compared using $\chi^{2}$ or Fisher's exact tests when appropriate. Logistic regression with Firth's correction was used to identify independent predictors of death. A univariate logistic regression was performed first. Statistically significant variables at a $20 \%$ threshold in the univariate analysis were introduced into the stepwise multivariate logistic regression model to select independent predictive factors for the end point. The ORs were reported with their 95\% CIs. The final model was evaluated for its predictive performance using the area under the ROC curve and was reported with its corresponding $95 \%$ CIs. To test the robustness of the model, internal validation was performed using bootstrap procedures (1000 bootstrap samples) to estimate over optimism associated with the area under the ROC curve and Brier scores (model scores range from 0 [perfect] to 0.25 [worthless]). The two-sided significance level was set at $5 \%$. Analyses were conducted using SAS version 9.2 software (SAS 


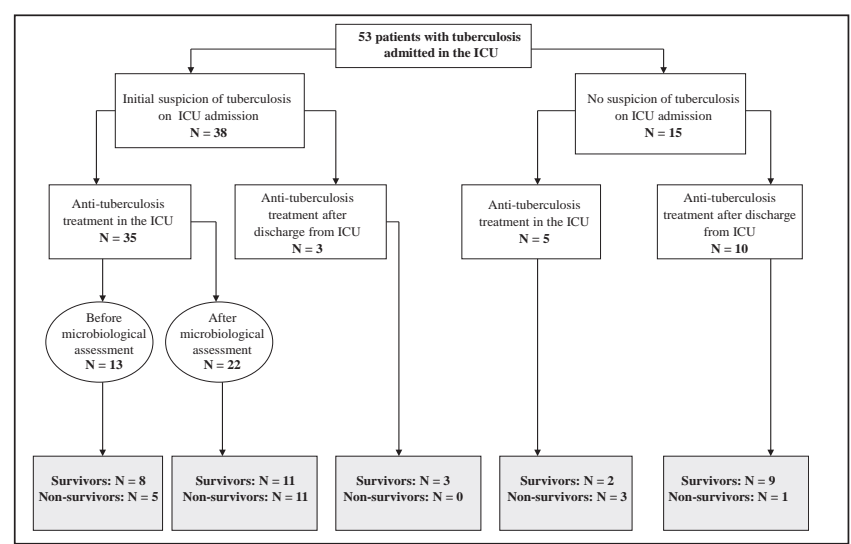

Figure 1) Flow chart of patients according to the initial suspicion of tuberculosis and antituberculosis treatment in the intensive care unit (ICU)

Institute Inc, USA) and R2.11 software (www.R-project.org); $\mathrm{P}<0.05$ was considered to be statistically significant.

\section{RESULTS}

\section{Patient characteristics}

During the 10-year period, 824 patients with tuberculosis were referred to and treated at the Hôpitaux de Paris, Hôpital Lariboisière, of whom 53 patients (median age 41 years IQR 32 to 52 years]; 40 men and 13 women) were included in the present study (Figure 1). Patients included smokers (62\%), alcohol abusers (42\%), drug addicts (12\%) and individuals infected with HIV (23\%). Approximately one-third (32\%) of the patients were homeless and one-half $(50 \%)$ were of African origin. Patients experienced chronic pulmonary disease (19\%), cancer (8\%) and type 2 diabetes $(4 \%)$. Symptoms on ICU admission included respiratory failure (57\%), altered consciousness (55\%; Glasgow Coma score $<10$ in $19 \%$ ), cardiovascular failure (42\%), meningeal syndrome (19\%), seizures (15\%) and renal injury (9\%). Patients presented with weight loss (83\%), fever (78\%; median temperature $38.7^{\circ} \mathrm{C}$ [IQR $37.6^{\circ} \mathrm{C}$ to $\left.39.6^{\circ} \mathrm{C}\right]$ ), cough $(63 \%)$, nightsweats $(56 \%)$, chest pain $(18 \%)$ and hemoptysis (10\%). Median serum C-reactive protein levels were $95 \mathrm{mg} / \mathrm{L}$ (IQR $32 \mathrm{mg} / \mathrm{L}$ to $188 \mathrm{mg} / \mathrm{L}$ ); hyponatremia was $58 \%$; median serum sodium concentration $134 \mathrm{mmol} / \mathrm{L}$ (IQR $128 \mathrm{mmol} / \mathrm{L}$ to $136 \mathrm{mmol} / \mathrm{L}$ ), and abnormal liver enzyme levels $(21 \%)$ were also observed. Eleven patients had received antibiotics before ICU admission, including beta-lactams $(n=7)$, fluoroquinolones $(n=3)$ and erythromycin $(n=1)$.

\section{Tuberculosis diagnosis}

Pulmonary tuberculosis was diagnosed in 51 of 53 patients (96\%), either during their stay in the ICU or in the medical wards. Two patients $(4 \%)$ presented with extrapulmonary tuberculosis without pulmonary involvement. Chest $\mathrm{x}$-rays showed alveolar pneumonia (50\%), nodules (25\%), miliary lesions (25\%), cavitary lesions $(23 \%)$, pleural effusion (29\%) and mediastinal lymphadenopathy (27\%). More than two lobes were involved in 28 of 53 patients $(53 \%)$. Tuberculous encephalomeningitis was diagnosed in 14 of 53 patients (26\%). Cerebral imaging revealed hydrocephalus (four of 14), abscesses (one of 14) and vasculitis (one of 14). Cerebrospinal fluid analysis showed a white blood cell count of $290 \times 10^{9} / \mathrm{L}$ (IQR $150 \times 10^{9} / \mathrm{L}$ to $366 \times 10^{9} / \mathrm{L}$ ), lymphocytes at $94 \%$ (IQR $86 \%$ to $97 \%$ ), a glucose level of $1.6 \mathrm{mmol} / \mathrm{L}$ (IQR $0.9 \mathrm{mmol} / \mathrm{L}$ to $2.0 \mathrm{mmol} / \mathrm{L}$ ) and a protein level of $2.5 \mathrm{~g} / \mathrm{L}$ (IQR $1.2 \mathrm{~g} / \mathrm{L}$ to $3.2 \mathrm{~g} / \mathrm{L}$ ). Other tuberculosis foci were diagnosed in 10 of 53 patients, including adenitis $(n=5)$ and spondylodiscitis $(n=2)$, and were also localized to the urogenitary system $(n=2)$ and bone marrow $(n=1)$. All tuberculosis diagnoses were confirmed by culture. Two strains were resistant to rifampin. The median duration between sampling and culture positivity was 19 days (IQR 10 to 29 days). One blood culture was positive for $M$ tuberculosis.
TABLE 2

Data comparisons according to the site where antituberculosis treatment was initiated

\begin{tabular}{|c|c|c|c|}
\hline & $\begin{array}{l}\text { Patients who } \\
\text { received anti- } \\
\text { tuberculosis } \\
\text { treatment in } \\
\text { the ICU }(n=40)\end{array}$ & $\begin{array}{l}\text { Patients } \\
\text { who did not } \\
\text { receive anti- } \\
\text { tuberculosis } \\
\text { treatment in the } \\
\text { ICU }(n=13)\end{array}$ & $\mathbf{P}$ \\
\hline \multicolumn{4}{|l|}{ Demographics and comorbidities } \\
\hline Age, years & $41(31-52)$ & $41(31-55)$ & 0.6 \\
\hline Sex ratio, male/female, $n / n$ & $30 / 10$ & $10 / 3$ & 0.9 \\
\hline HIV infection, n (\%) & $9(23)$ & $3(23)$ & 0.8 \\
\hline Chronic pulmonary diseases, n (\%) & $6(15)$ & $4(31)$ & 0.7 \\
\hline Alcohol abuse, n (\%) & $14(35)$ & $8(62)$ & 0.02 \\
\hline Drug addiction, n (\%) & $3(8)$ & $3(23)$ & 0.1 \\
\hline \multicolumn{4}{|l|}{ Clinical findings on ICU admission } \\
\hline Temperature, ${ }^{\circ} \mathrm{C}$ & $38.7(37.5-39.5)$ & $38.4(37.6-39.8)$ & 0.8 \\
\hline Glasgow Coma score & $14(10-15)$ & $15(14-15)$ & 0.2 \\
\hline Systolic blood pressure, $\mathrm{mmHg}$ & $96(80-120)$ & $105(89-112)$ & 0.5 \\
\hline Heart rate, beats/min & $124(108-139)$ & 128 (99-147) & 0.7 \\
\hline Respiratory rate, breaths/min & $32(27-38)$ & $30(24-37)$ & 0.6 \\
\hline SAPS II & $32(24-55)$ & $28(22-40)$ & 0.2 \\
\hline \multicolumn{4}{|l|}{ Management and outcome } \\
\hline Mechanical ventilation, n (\%) & $24(60)$ & $3(23)$ & 0.02 \\
\hline Vasopressor infusion, n (\%) & $20(33)$ & $2(15)$ & 0.03 \\
\hline Length of ICU stay, days & $9(5-18)$ & $3(3-5)$ & 0.004 \\
\hline Hospital-acquired infections, n (\%) & $11(28)$ & $0(0)$ & 0.03 \\
\hline
\end{tabular}

Data presented as median (interquartile range) unless otherwise indicated. Bolded values indicate statistical significance. ICU Intensive care unit; SAPS II Simplified Acute Physiology score II

\section{ICU management}

The median duration of ICU stay was six days (IQR three to 16 days). Management included mechanical ventilation (51\%; median duration six days [IQR three to 17 days]), vasopressors (42\%), corticosteroids (50\%), hemodialysis (17\%) and pulmonary embolization (4\%). Among ventilated patients, eight were initially treated with noninvasive ventilation; however, all eventually required intubation. Quadruple antituberculosis therapy was administered in the ICU (75\%) with a median three-day (IQR zero to 21 days) delay after admission. Diagnosis was made after ICU transfer to the medical wards (25\%) and antituberculosis therapy was continued. In these cases, the diagnosis on ICU discharge was bacterial pneumonia $(n=8)$, pleural lymphocytic effusion $(n=3)$, pneumocystosis in an HIV-infected patient $(n=1)$ and cardiogenic pulmonary edema $(n=1)$.

\section{Outcome and prognostic factors}

Eleven patients developed mechanical ventilation-acquired pneumonia (Pseudomonas aeruginosa, 33\%). Twenty patients (38\%) died in the ICU. Death was related to tuberculosis-induced ARDS or cardiovascular failure $(n=5)$, pulmonary coinfections $(n=4)$, hospital-acquired pneumonia $(n=10)$ and massive pulmonary embolism $(n=1)$. The univariate analysis is shown in Table 1. Comparisons between patients who received antituberculosis therapy in the ICU and those who were treated after transfer to the medical ward are shown in Table 2. Using a logistic regression model, three independent factors on ICU admission were associated with mortality: miliary pulmonary tuberculosis, mechanical ventilation and vasopressor requirement (Table 3). The area under the ROC curve of our model was 0.92 (95\% CI 0.84 to 0.99). The area under the ROC curve-associated optimism, evaluated using a bootstrap procedure, was $3 \%$ and the bias-corrected Brier score was moderate and equal to 0.13 . The output from the multivariate logistic regression was used to build a simple score by summing the three independent variables (Table 4). This score was effective for predicting fatality rate with an area under the ROC curve of 0.92 (95\% CI 0.85 to 0.98) (Table 5). 
TABLE 3

Logistic regression analysis to predict final outcome (survival versus death) based on clinical findings on intensive care unit (ICU) admission in Mycobacterium tuberculosis-infected patients

\begin{tabular}{|c|c|c|c|c|}
\hline \multirow[b]{2}{*}{ Variable } & \multicolumn{2}{|c|}{ Univariate analysis } & \multicolumn{2}{|c|}{ Multivariate analysis } \\
\hline & OR $(95 \% \mathrm{Cl})$ & $\mathbf{P}$ & OR $(95 \% \mathrm{Cl})$ & $\mathbf{P}$ \\
\hline Temperature & $0.7(0.48-1.04)$ & 0.08 & & \\
\hline Glasgow Coma score & $0.81(0.68-0.97)$ & 0.02 & & \\
\hline Systolic blood pressure & $0.96(0.94-0.99)$ & 0.02 & & \\
\hline Heart rate & $1.01(0.99-1.03)$ & 0.3 & & \\
\hline Respiratory rate & $1.08(1.01-1.15)$ & 0.03 & & \\
\hline SAPS II & $1.06(1.02-1.1)$ & 0.002 & & \\
\hline C-reactive protein & $1(1-1.01)$ & 0.1 & & \\
\hline $\mathrm{PaO}_{2} / \mathrm{FiO}_{2}$ & $0.99(0.99-1)$ & 0.002 & & \\
\hline Plasma lactate concentration & $1.29(0.96-1.74)$ & 0.09 & & \\
\hline Prothrombin ratio & $0.96(0.93-0.99)$ & 0.02 & & \\
\hline Hemoglogin & $0.83(0.66-1.04)$ & 0.1 & & \\
\hline Renal injury & $5.91(0.72-48.77)$ & 0.1 & & \\
\hline Multilobar involvement ( $\geq 3$ lobes) & $7.73(1.95-30.68)$ & 0.004 & & \\
\hline Miliary tuberculosis & $3.52(0.96-12.94)$ & 0.06 & $9.04(1.25-65.30)$ & 0.03 \\
\hline Catecholamine infusion & $22.68(4.53-113.48)$ & $<0.0001$ & $8.45(1.29-55.18)$ & 0.03 \\
\hline Mechanical ventilation & $17.67(4.22-73.89)$ & $<0.0001$ & $11.36(1.55-83.48)$ & 0.02 \\
\hline
\end{tabular}

$\mathrm{PaO}_{2} / \mathrm{FiO}_{2}$ Ratio of partial pressure of arterial oxygen to the fraction of inspired oxygen; SAPS II Simplified Acute Physiology Score II

TABLE 4

The distribution of a simple intensive care unit (ICU) tuberculosis score to predict death in tuberculosis-infected patients admitted to the ICU

\begin{tabular}{lcc}
\hline ICU tuberculosis score & Survivors $(\mathbf{n}=\mathbf{3 3})$ & Nonsurvivors $(\mathbf{n}=\mathbf{2 0})$ \\
\hline 0 & $22(67)$ & $0(0)$ \\
1 & $8(24)$ & $5(25)$ \\
2 & $3(9)$ & $12(60)$ \\
3 & $0(0)$ & $3(15)$
\end{tabular}

Data presented as $n$ (\%). *The score (values from 0 to 3 ) is based on the sum of three parameters: military tuberculosis (yes: +1 , no: 0 ), required mechanical ventilation on ICU admission (yes: +1 , no: 0 ), and required vasopressor infusion (yes: +1 , no: 0 )

\section{DISCUSSION}

In a series of tuberculosis patients admitted to the ICU in France, we found an elevated death rate $(38 \%)$. We demonstrated that miliary tuberculosis, mechanical ventilation and vasopressor requirement on ICU admission were predictive of a fatal outcome. We determined a simple scoring system that was predictive of fatality based on these three independent factors.

The major features of patients with tuberculosis requiring ICU admission included acute respiratory distress, altered consciousness and cardiovascular failure. A recent study (3) reported the following primary causes for ICU admission in 67 patients with tuberculosis in Brazil: respiratory failure (63\%), cardiopulmonary arrest (10\%), septic shock (7\%), sepsis (6\%) and altered sensorium (6\%). Another study involving 99 patients (7) assessed the presence of shock, neurological disorders and renal failure in addition to acute respiratory failure, in $20 \%, 18 \%$ and $10 \%$ of the patients with active pulmonary tuberculosis admitted to the ICU, respectively. In our series, respiratory failure was the primary cause for patient admission (57\%). Tuberculosis is a rare cause of ARDS, representing approximately $4.9 \%$ of the cases in one series (11). Among patients with pulmonary tuberculosis, those with miliary and disseminated forms are more likely to require mechanical ventilation and develop ARDS (7). Altered consciousness was present in $55 \%$ of our patients. Of these patients, 14 had tuberculous meningitis with abnormal neuroradiological findings including hydrocephalus, meningeal hyperfixation and abscesses in one-half of the cases. In the remaining 15 patients, neurological disorders were related to severe sepsis and hypoxemia in the absence of meningitis and abnormal computed tomography scans. Cardiovascular failure (42\%) was
TABLE 5

Validation of a simple intensive care unit (ICU) tuberculosis (TB) score to predict death in TB-infected patients admitted to the ICU

\begin{tabular}{lccccc}
\hline ICU TB & & & \multicolumn{2}{c}{ Predictive value } & \\
\cline { 4 - 5 } score & Sensitivity, & Specificity & Positive & Negative & Accuracy \\
\hline 0 & - & - & - & - & - \\
1 & $100(83-100)$ & $67(48-82)$ & $65(45-81)$ & 100 & $79(66-89)$ \\
& & & $(85-100)$ & \\
2 & $75(51-91)$ & $91(76-98)$ & $83(59-96)$ & $86(70-95)$ & $85(72-93)$ \\
3 & $15(3-38)$ & $100(89-100) 100(29-100)$ & $66(51-79)$ & $68(54-80)$ \\
\hline $\begin{array}{l}\text { Data presented as median \% (interquartile range). The ICU TB score (values } \\
\text { from 0 to 3) is based on the sum of three parameters: military tuberculosis (yes }\end{array}$ \\
$=1 ;$ no = 0), required mechanical ventilation on ICU admission (yes = 1; no =0) \\
and required vasopressor infusion (yes = 1; no = 0).
\end{tabular}

related to sepsis, mainly due to bacterial coinfections and only rarely to $\mathrm{M}$ tuberculosis, suggesting a major role for associated pulmonary infections in the acute presentation of tuberculosis requiring ICU admission.

We found a mortality rate of $38 \%$, which appears to be consistent with what has been reported previously in the literature (22\% to $69 \%)(2-8,12)$. Mortality differed among these series according to the proportion of mechanically ventilated patients and extrapulmonary involvements. Consistently, Erbes et al (5) found a mortality rate of $66 \%$, while greater than $90 \%$ of their patients required mechanical ventilation. Similarly, $68 \%$ of the 59 mechanically ventilated tuberculosis patients in a Taiwanese study (5) died. In contrast, when the rate of ventilated patients was lower $(37.9 \%)$, mortality rate among tuberculosis patients was reduced (22.4\%). In ventilated patients, the mortality rate with tuberculosis is nearly twice that for usual bacterial pneumonia (7). Of the patients who died in our series, $25 \%$ died directly from $M$ tuberculosis-associated ARDS or septic shock without evidence of any other bacterial infection, as has been previously described among immunocompetent patients $(13,14)$. However, death generally resulted from community-acquired bacterial coinfections or ventilator-associated pneumonia. Interestingly, all cases of hospital-acquired pneumonia, except one, led to the patients' death, due to the severity of the underlying tuberculosis damage affecting the lungs. Contributions from hospital-acquired infection, particularly with Gram-negative bacteria, in tuberculosis death has been suggested (4). Lin et al (12) found that nosocomial pneumonia was 
independently associated with in-hospital mortality. Surprisingly, in one report, ventilation-associated pneumonia was found to be protective for mortality; however, its contribution to death was noted to be a confounding factor due to the long duration of mechanical ventilation in survivors (2).

In our study, prognosticators of fatality on ICU admission were miliary pulmonary tuberculosis, mechanical ventilation (mainly for acute respiratory distress) and cardiovascular failure requiring vasopressors within the first $24 \mathrm{~h}$. We were able to determine a simple predictive fatality score in patients with active tuberculosis admitted to the ICU. To the best of our knowledge, no scoring system has been published. In the literature, other clinical parameters have been significantly associated with death in the ICU, including high Acute Physiology and Chronic Health Evaluation (APACHE) II or SAPS II scores, sepsis, organ failure (ARDS and acute renal failure), hypoalbuminemia $(<20 \mathrm{~g} / \mathrm{L})$ and multilobar involvement (2-8). Predicted mortality based on our score was significantly higher than what was predicted using SAPS II, except for class 0 . This observation supports the notion that differences exist between both models regarding tuberculosis patients and, as previously shown, that SAPS II can underestimate mortality $(7,15)$. Interestingly, a Sequential Organ Failure Assessment (SOFA) score was evaluated as being a valuable prognostic indicator in ICU patients with ARDS caused by miliary tuberculosis (16). Thus, we believe that our score could be complementary to SOFA and SAPS II scores, allowing for better assessment of the final prognosis for such patients. However, in contrast to our findings showing that miliary tuberculosis was predictive of death, Ki et al (17) did not find any differences regarding mortality among 66 patients with tuberculous pneumonia and 24 with miliary tuberculosis, while shock and advanced age were associated with poor outcome. Late admission to the ICU, as well as delayed treatment ( $>1$ month after symptom onset), have also been recognized as risk factors for death $(2,5,6)$. Similarly, in another study including 99 ICU patients in France (7), delayed treatment was assessed as an independent predictor of threeday mortality with an OR of 3.73. In contrast, similar to our study, comorbidities including chronic obstructive pulmonary disease, alcohol abuse, cancer and HIV infection did not impact tuberculosis mortality rate in the ICU (2-8). HIV-infected patients have been reported to be more likely to have extrapulmonary, disseminated and miliary tuberculosis (18). In our study, HIV-infected patients (23\%) were severely immunocompromised (CD4 T lymphocyte count $<200 \times 10^{9} / \mathrm{L}$ ) with a high incidence of extrapulmonary forms (50\%); their mortality rate was comparable with non-HIV infected patients.

Tuberculosis patients are generally admitted to the ICU because of life-threatening symptoms requiring immediate supportive management including mechanical ventilation and vasopressors. Noninvasive ventilation has been shown to be effective in several cases of $M$ tuberculosisrelated ARDS (19). In the present study, noninvasive pressure support ventilation was initiated in eight patients; however, all of them ultimately required intubation. Delayed diagnosis of tuberculosis is also common in the ICU. In one series, diagnosis was obtained on postmortem findings in three of 61 tuberculosis patients admitted to the ICU (8). In our series, $25 \%$ of patients did not receive antituberculosis antibiotics until after transfer from the ICU to the medical wards. These patients

\section{REFERENCES}

1. WHO Global Tuberculosis Control Report 2009. <www.who.int/tb/ publications/global_report/2009/pdf/full_report.pdf> (Accessed March 13, 2010).

2. Frame RN, Johnson MC, Eichenhorn MS, Bower GC, Popovich J Jr. Active tuberculosis in the medical intensive care unit: A 15-year retrospective analysis. Crit Care Med 1987;15:1012-4.

3. Silva DR, Menegotto DM, Schulz LF, Gazzana MB, Dalcin PT. Mortality among patients with tuberculosis requiring intensive care: A retrospective cohort study. BMC Infect Dis 2010;10:54.

4. Ryu YJ, Koh WJ, Kang EH, et al. Prognostic factors in pulmonary tuberculosis requiring mechanical ventilation for acute respiratory failure. Respirology 2007;12:406-11. presented with acute respiratory distress or features that were related to either nontuberculosis bacterial pneumonia or noninfectious etiologies. Direct $M$ tuberculosis staining and polymerase chain reaction tests were negative. They received general antibiotics and supportive care, which were effective treatments leading to improvement and transfer out of the ICU, despite no prophylactic antituberculosis treatment. Interestingly, the median delay for positive cultures was 19 days, while the median length of ICU stay was six days. Atypical presentations, including consolidations or absence of any abnormalities on chest radiographs, are known to be underdiagnosed (5,6). A long duration of respiratory symptoms before ICU admission in severe pneumonia should heighten suspicion for possible undiagnosed pulmonary tuberculosis (14). Fortunately, none of our patients with undiagnosed pulmonary tuberculosis died after transfer to the medical ward, despite treatment delay, which has been shown to worsen outcomes $(3,6,7,20)$. Surprisingly, delayed diagnosis and initiation of quadruple antituberculosis therapy were not associated with a worsening prognosis in our study. These patients appeared to be less critically ill on ICU admission, with a significantly lower need for vasopressors and mechanical ventilation and a subsequently shorter length of ICU stay (Table 2). We acknowledge that this finding may represent a bias - patients with atypical presentations, negative direct microbiological tests and no life-threatening symptoms received specific antibiotics only after microbiological evidence of tuberculosis. In contrast, tuberculosis associated with lung damage and miliary forms of tuberculosis were more rapidly treated with antituberculosis therapy.

Our study has significant limitations related to its retrospective nature and single-centre methodology. Our study may have been underpowered due to the small number of patients. Patients with massive hemoptysis were not admitted to our hospital because embolization is not available in our hospital. Due to our inclusion criteria and to the retrospective nature of our study, the definitive contribution of tuberculosis to critical illness requiring ICU admission may be difficult to assess. The partial reversibility of ICU-precipitating events in 13 patients who did not receive specific antituberculosis treatment may argue against a direct role for tuberculosis in determining the final ICU outcome. However, based on a case-by-case analysis, we estimated that tuberculosis significantly contributed to critical illness of all our patients. Finally, we were not able to analyze the consequences of resistance to antituberculosis agents because only two patients had rifampicin-resistant strains.

\section{CONCLUSIONS}

Despite available effective treatments, tuberculosis may still require ICU admission and result in high fatality rates in the 21 st century, even in a developed country such as France. Miliary pulmonary tuberculosis, mechanical ventilation and vasopressor requirements on admission were associated with increased mortality, with hospitalacquired infections worsening prognosis. Physicians should be aware of atypical tuberculosis presentations on ICU admission and maintain high clinical suspicion, even despite initially negative microbiological tests.

DISCLOSURES: The authors have no financial disclosures or conflicts of interest to declare.

5. Erbes R, Oettel K, Raffenberg M, Mauch H, Schmidt-Ioanas M, Lode H. Characteristics and outcome of patients with active pulmonary tuberculosis requiring intensive care. Eur Respir J 2006;27:1223-8.

6. Lee PL, Jerng JS, Chang YL, et al. Patient mortality of active pulmonary tuberculosis requiring mechanical ventilation. Eur Respir J 2003;22:141-7.

7. Zahar JR, Azoulay E, Klement E, et al. Delayed treatment contributes to mortality in ICU patients with severe active pulmonary tuberculosis and acute respiratory failure. Intensive Care Med 2001;27:513-20.

8. Penner C, Roberts D, Kunimoto D, Manfreda M, Long R. Tuberculosis as a primary cause of respiratory failure requiring mechanical ventilation. Am J Respir Crit Care Med 1995;151:867-72. 
9. Bellomo R, Ronco C, Kellum JA, Mehta RL, Palevsky P; Acute Dialysis Quality Initiative workgroup. Acute renal failure definition, outcome measures, animal models, fluid therapy and information technology needs: The Second International Consensus Conference of the Acute Dialysis Quality Initiative (ADQI) Group. Crit Care 2004;8:R204-12.

10. Le Gall JR, Lemeshow S, Saulnier F. A new simplified acute physiology score (SAPS II) based on a European/North American multicenter study. JAMA 1993;270:2957-63.

11. Agarwal R, Gupta D, Aggarwal AN, Behera D, Jindal SK. Experience with ARDS caused by tuberculosis in a respiratory intensive care unit. Intensive Care Med 2005;31:1284-7.

12. Lin SM, Wang TY, Liu WT, et al. Predictive factors for mortality among non-HIV-infected patients with pulmonary tuberculosis and respiratory failure. Int J Tuberc Lung Dis 2009;13:335-40.

13. Michel P, Barbier C, Loubière Y, Hayon JH, Ricôme JL. Three cases of septic shock due to tuberculosis without VIH pathology. Intensive Care Med 2002;28:1827-8.

14. Ahuja SS, Ahuja SK, Phelps KR, Thelmo W, Hill AR. Hemodynamic confirmation of septic shock in disseminated tuberculosis. Crit Care Med 1992;20:901-3.
15. Roodt A, Smith C, Feldman C et al. APACHE II severity of illness score in patients with severe active pulmonary tuberculosis. S Afr J Crit Care 1990;6:13-14.

16. Lee K, Kim JH, Lee WY, et al. Acute respiratory distress syndrome caused by miliary tuberculosis: A multicentre survey in South Korea. Int J Tuberc Lung Dis 2011;15:1099-103.

17. Ki YJ, Pack KM, Jeong E, et al. Pulmonary tuberculosis with acute respiratory failure. Eur Respir J 2008;32:1625-30.

18. Hui C, Wu CL, Chan MC, Kuo IT, Chiang CD. Features of severe pneumonia in patients with undiagnosed pulmonary tuberculosis in an intensive care unit. J Formos Med Assoc 2003;102:563-9.

19. Agarwal R, Gupta D, Handa A, Aggarwal AN. Non invasive ventilation in ARDS caused by Mycobacterium tuberculosis: Report of three cases and review of the literature. Intensive Care Med 2005;31:1723-24.

20. Mert A, Bilir M, Tabak F, et al. Miliary tuberculosis: Clinical manifestations, diagnosis and outcome in 38 adults. Respirology 2001;6:217-24 


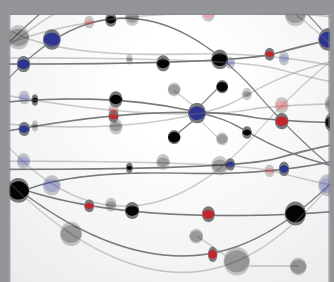

The Scientific World Journal
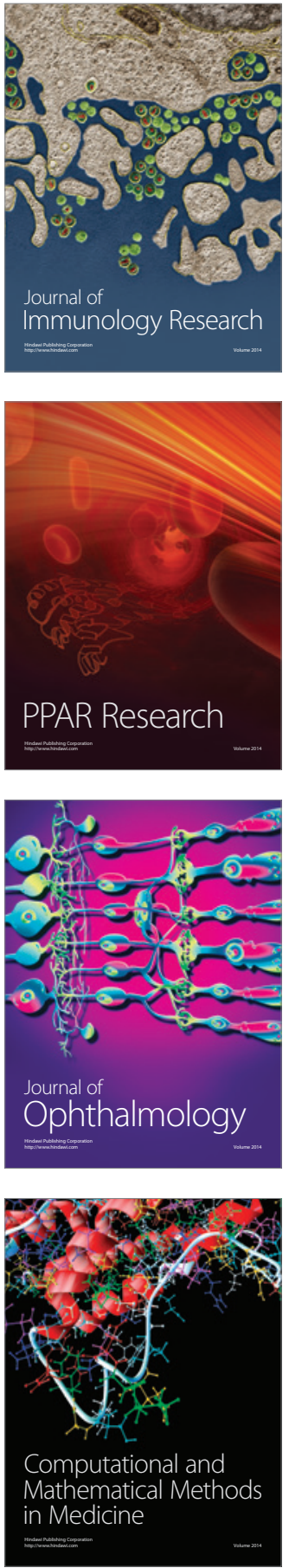

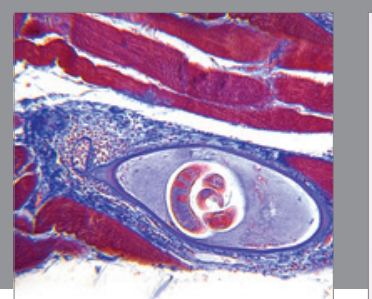

Gastroenterology Research and Practice

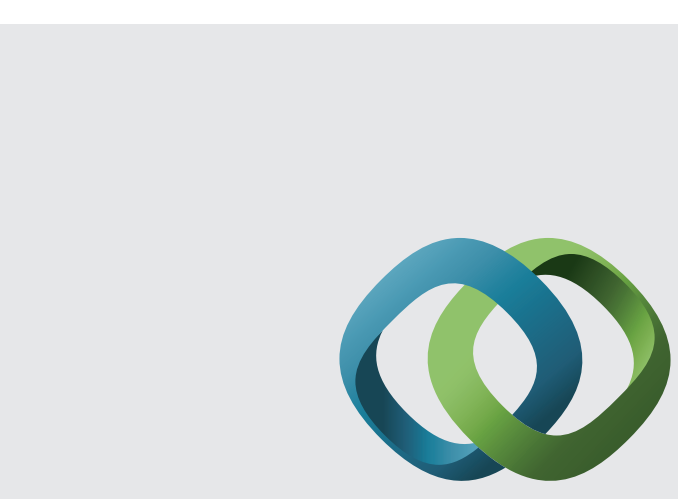

\section{Hindawi}

Submit your manuscripts at

http://www.hindawi.com
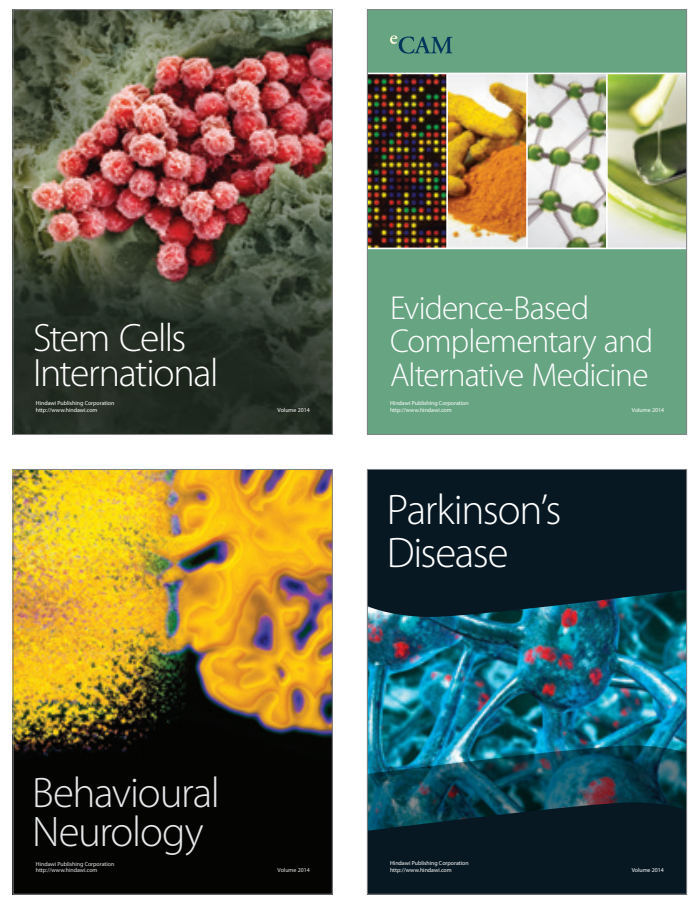
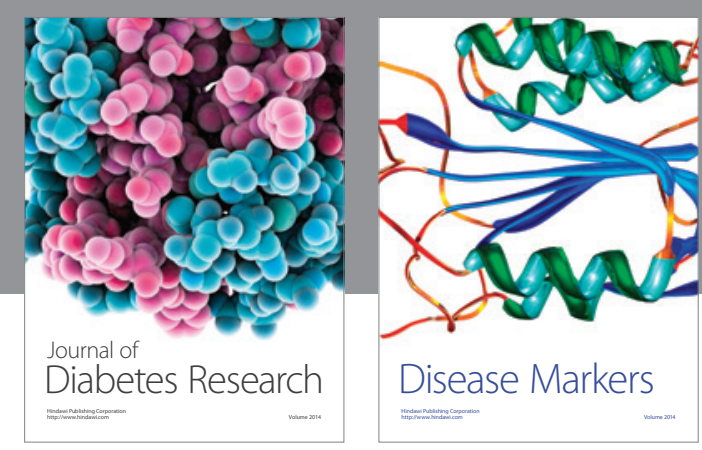

Disease Markers
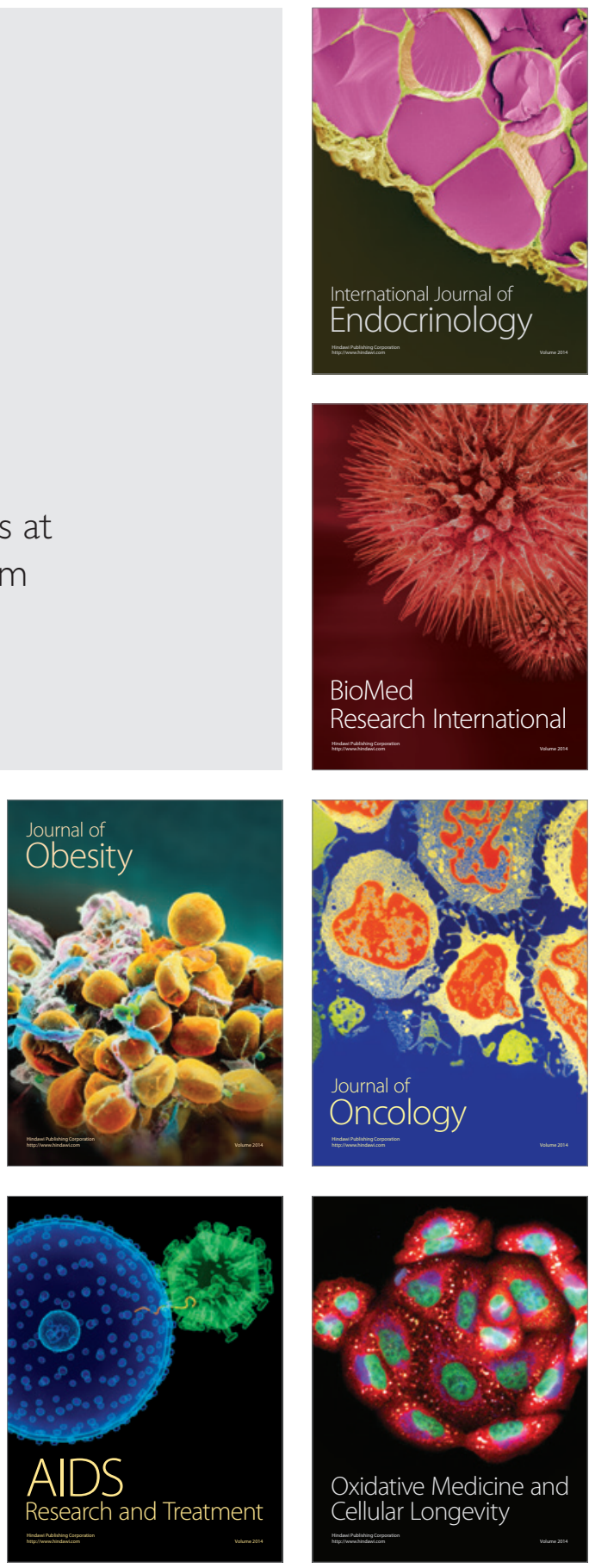